\title{
Protective Potential of Ginseng and/or Coenzyme Q10 on Doxorubicin-induced Testicular and Hepatic Toxicity in Rats
}

\author{
Suzan Khodir $^{1}$, Aliaa Alafify² ${ }^{2}$, Essam $\operatorname{Omar}^{1}$ (D), Marwa Al-Gholam²* (D) \\ ${ }^{1}$ Department of Medical Physiology, Faculty of Medicine, Menoufia University, Shebin El-Kom, Menoufia, Egypt; ${ }^{2}$ Department \\ of Anatomy and Embryology, Faculty of Medicine, Menoufia University, Shebin El-Kom, Menoufia, Egypt
}

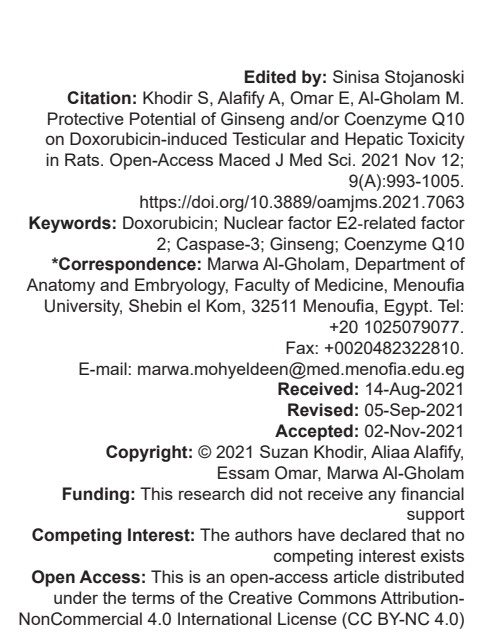

Introduction

According to the global statistics, the neoplasm is one of the main reasons for morbidity and mortality worldwide. Frequently encountered issues are seeking medical care in late stages of the disease and inaccessibility of diagnosis. Despite the active development of various approaches to cancer treatment, systemic chemotherapy remains the mainstay cancer treatment. The pharmacological development in the second half of the $20^{\text {th }}$ century led to a stable annual increase in the life expectancy of cancer patients [1]. The anthracycline antibiotic doxorubicin (DOX) is one of the applied antitumor agents against human malignancies [2]. However, many toxic adverse effects of DOX on organs, such as the liver and testis, have also been established [3]. DOX could impede spermatogenesis [4]. The liver is the chief detoxifying tissue; therefore, it is the target of excessive amounts of genotoxic composites and anticancer drugs including DOX. Approximately $40 \%$ of patients on DOX suffer from liver injury and can result in liver failure and death [3]. Thus, it is critically important to understand how DOX impairs organ function to generate targeted interventions to improve health outcomes [5].

The main mechanism of DOX-induced cytotoxicity is due to the generation of reactive oxygen species (ROS) [6]. Maintaining the balance between the production of ROS and the availability of antioxidant enzymes, such as superoxide dismutase (SOD), is consequently critical. This could be an important mechanism for preventing oxidative stress-induced tissue damage. Another mechanism is cellular apoptosis in the liver and testes following DOX treatment [7].

Many genes and signaling pathways play a mechanistic role in the pathogenesis of Dox-induced cytotoxicity. Nuclear factor E2-related factor 2 (Nrf2) is referred to as the master regulator of the antioxidant response. It modulates the expression of a series of genes encoding antioxidant proteins expression through the antioxidant response element (ARE) in the liver [8]. Under normal conditions, Nrf2 binds to the kelch-like ECH-associated protein 1 (Keap1) in the cytoplasm [9]. In response to oxidative or electrophilic stress, Keap1 is oxidized resulting in decreased affinity for Nrf2, which allows it to accumulate in the nucleus 
to induce the detoxifying and antioxidant defense genes expression [10]. DOX exposure also activates the expression of nuclear factor kappa B cell (NF-kB) which in turn releases pro-inflammatory mediator, including tumor necrosis factor-alpha (TNF- $\alpha$ ) [11]. These inflammation factors have been thought to be the focus of investigating inflammatory injury. Thus, activating the Nrf2 signaling pathway and inhibiting inflammatory response might be a beneficial molecular target to prevent DOX-induced organ injury.

Controlling the oxidative injury by a variety of antioxidant or anti-apoptotic agents has been employed to counteract Dox-induced damage [12]. Nevertheless, so far, there is still no single agent proven effective enough to prevent or reverse this adverse effect. Ginseng is a medicinal herbal plant that has been used for thousands of years as an adaptogen to increase physical energy and enhance fertility [13] and hepatoprotective activities [14]. The pharmacological properties of ginseng are mainly attributed to ginsenosides [15]. Ginsenosides are bioactive compounds that have antioxidant, anti-inflammatory [16], hypocholesterolemic, and hypolipidemic effects [17].

Coenzyme Q10 (CoQ10) is an important cellular antioxidant. [18], with free radical scavenging activities [19] and anti-inflammatory effects [20]. CoQ10 can modulate the expression of Nrf2 after exercise training, supporting the role of CoQ10 in antioxidant defense and inflammation [21].

Therefore, both ginseng and CoQ10 have the potential to protect against tissue injury induced by DOX. This encouraged us to conduct the present study to evaluate the testicular and hepatoprotective effect of ginseng and/or CoQ10 in rats exposed to DOX and the possible underlying mechanisms. In addition, we investigated the impact of DOX-induced cytotoxicity on Nrf2 expression in testis and liver, and whether it has been improved by ginseng and/or CoQ10 treatment or not as a suggested mechanism of action.

\section{Materials and Methods}

\section{Animals}

This study was carried out following the regulations of the Animal Experimentation Ethics Committee of the Faculty of Medicine Menoufia University. Fifty adult male Wister rats weighing 150 $180 \mathrm{~g}$ were used. The animals were housed at $20-24^{\circ} \mathrm{C}$ with a $12 \mathrm{~h}$ light and $12 \mathrm{~h}$ dark cycle and they were provided with standard rat chow and tap water freely available. Rats were allowed to acclimatize for 10 days before the start of experiments.

\section{Experimental design}

Rats were randomly divided into five groups (10 rats each):

1. Control group: Rats received a single intraperitoneal (i.p.) injection of $1 \mathrm{ml}$ normal saline for each rat

2. DOX group: DOX-induced testicular and hepatic toxicity was achieved by a single intraperitoneal injection of each rat by DOX in a dose of $15 \mathrm{mg} / \mathrm{kg}$ [22], [23]. DOX, a product of HIKMA specialized pharmaceuticals Badr city, Cairo, Egypt, was available in the form of a vial with the trade name "Adricin." Each vial contains DOX HCL 50 mg/25 ml

3. DOX/ginseng treated (DOX/Gin) group: Rats received the combination of a single dose of DOX (15 mg/kg, i.p.) and ginseng a product of EIPICO, $10^{\text {th }}$ of Ramadan city, Sharkia, Egypt (under license of Pharmaton SA, Lugano, Switzerland), was available in the form of capsules with the trade name "Ginsana." Each capsule contained $100 \mathrm{mg}$ of ginseng. The contents of the capsule were withdrawn by a syringe and dissolved in distilled water and given to the rats in a dose of $400 \mathrm{mg} / \mathrm{kg}$ once daily for 4 weeks by oral gavage [24]

4. DOX/CoQ10 treated (DOX/CoQ10) group: Rats received the combination of a single dose of DOX (15 mg/kg, i.p.) and CoQ10 (MEPACO, Egypt). CoQ10 was dissolved in distilled water and given orally by gavage in a dose of (10 mg/kg/day) for 4 weeks [22], [25]

5. DOX/ginseng+CoQ10treated(DOX/Gin+CoQ10) group: Rats received the combination of a single dose of DOX (15 mg/kg, i.p.) and both of ginseng (400 mg/kg/day) and CoQ10 (10 mg/kg/day) for 4 weeks.

All treatments were started on the next day of DOX injection. At the end of the study, all rats were weighed and blood samples were withdrawn for subsequent biochemical analysis. Thereafter, all rats were sacrificed, and liver and testis were quickly dissected after being weighed.

The organ indices were calculated by the following formula:

$$
\text { Organ index }=\frac{\text { Organ weight }}{\text { Body weight }} \times 100
$$

The right lobe of the liver and part of the right testis were stored at $-80^{\circ} \mathrm{C}$ for real-time PCR analysis of the nrf2 gene. The remaining part of the right testis and lobe of the liver was homogenized for biochemical analysis while the left testis and remaining part of the liver were prepared for histological and immunohistochemical analyses. 


\section{Blood sampling and biochemical analysis}

At the end of the study period, animals have fasted overnight, and then, retro-orbital blood samples were collected, allowed to coagulate for $30 \mathrm{~min}$ at room temperature, and then centrifuged at $2000 \mathrm{rpm}$ for $15 \mathrm{~min}$. Serum was collected and frozen at $-80^{\circ} \mathrm{C}$ until analyzed.

Serum interleukin 10 (IL-10), serum interleukin 6 (IL-6), serum TNF- $\alpha$, and serum testosterone levels were measured using the corresponding rat enzyme-linked immunosorbent assay kits (IL-10: ERI3010-1, Assaypro LLC, Saint Charles, Missouri, USA), (TNF- $\alpha$ : ERT2010-1, Assaypro LLC, Saint Charles, Missouri, USA), (IL-6: ab100772, Abcam, Cambridge, UK), (Testosterone: ab108666, Abcam, Cambridge, UK) according to the manufacturer's instructions. Tissue malondialdehyde (MDA), tissue SOD, serum liver enzymes (alanine transaminase [ALT], aspartate transaminase [AST], alkaline phosphatase [ALP], gamma-glutamyl transferase [GGT]), fasting serum cholesterol, and fasting serum triglyceride (TG) were determined using colorimetric kits (Biodiagnostic Company, Dokki, Giza, Egypt).

\section{Tissue homogenate preparation}

Specimens from the liver and testis were weighted and homogenized separately with a tissue homogenizer (MPW120, MPW Medical Instruments, China). For estimation of tissue MDA level, tissues were homogenized in phosphate buffer saline $50 \mathrm{mM}$ $\mathrm{pH}$ 7.4. For the estimation of SOD, tissues were homogenized in potassium phosphate buffer $10 \mathrm{mM}$ $\mathrm{pH}$ 7.4. The crude tissue homogenate was centrifuged at $10,000 \mathrm{rpm}$, for $15 \mathrm{~min}$ in an ice-cold centrifuge, and the resultant supernatant was collected and stored at $-80^{\circ} \mathrm{C}$ for assay.

\section{Quantitative assay of gene expression} using reverse transcriptase polymerase chain reaction technique (RT-PCR)

Relative mRNA levels of the Nrf2 gene in the liver and testis were analyzed by RT-PCR. Total RNA was extracted from tissues using TRIzol reagent (Invitrogen, Carlsbad, CA, USA) according to the manufacturer's instructions. Extracted RNA was stored at $-80^{\circ} \mathrm{C}$ till the time of use. The first step, PCR was complementary DNA (cDNA) synthesis (reverse transcription step) using the ThermoScript ${ }^{\mathrm{TM}}$ RT reagent kits (Invitrogen). Then, cDNAs were amplified by PCR assays with SYBR Green Mix kits (Stratagene, USA). A cycle threshold $(\mathrm{Ct})$ value was obtained from each amplification curve. Glyceraldehyde-3-phosphate dehydrogenase was used as the reference gene. Data analysis was done using 7500 ABI PRISM (Applied Biosystems, USA) v.2.0.1. The relative quantification of Nrf2 gene expression was calculated using the comparative $\Delta \Delta \mathrm{Ct}$ method [27]. The primers employed for the Nrf2 gene were as follows:

- $\quad$ Forward primer:
5'-AGCAAGACTTGGGCCACTT-3'
Reverse primer:
5'-GATGGAGGTTTCTGTCGTTTTC-3'

\section{Histopathological analysis}

Fresh specimens of the right lobe of the liver and the left testis were collected and fixed immediately in $10 \%$ neutral buffered formalin. Paraffin sections (5 $\mu \mathrm{m}$ in thickness) were prepared and stained with $\mathrm{H} \& \mathrm{E}$ to verify histological details [28].

The primary monoclonal antibody was the mouse monoclonal primary antibody to caspase-3 (Ab-7, Mouse Mab. MS.). The cellular reaction appeared as brownish cytoplasm of the cells.

Immunostaining for caspase-3 was performed according to the manufacturer's instructions. Briefly, $5 \mu \mathrm{m}$ sections of liver and testis were deparaffinized, rehydrated, rinsed in tap water, and embedded in 3\% $\mathrm{H} 2 \mathrm{O} 2$ for $10 \mathrm{~min}$ to block endogenous peroxidase. Sections were immersed in an antigen retrieval solution (10 $\mathrm{mmol} / \mathrm{l}$ sodium citrate buffer, $\mathrm{pH} 6$ ) and subjected to heat-induced antigen retrieval for $20 \mathrm{~min}$ in a microwave. Non-specific protein binding was blocked by a blocking solution (phosphate-buffered saline [PBS] and 10\% normal goat serum). The slides were incubated with the diluted primary antibody (caspase-3, Abcam, working dilution 1:500). Sections were incubated with secondary biotinylated antibodies (goat anti-mouse IgG; Sigma Aldrich, St. Louis, USA) for $20 \mathrm{~min}$. The streptavidin-peroxidase complex was then applied to sections for $10 \mathrm{~min}$. The secondary antibody binding was visualized by incubating sections with 3, 3-diaminobenzidinetetrahydrochloride (DAB; Sigma Aldrich, St. Louis, USA). Finally, slices were rinsed with PBS. Finally, the sections were counterstained with hematoxylin $(\mathrm{H})$, dehydrated, and coverslipped.

\section{Statistical analysis}

The data were tabulated and analyzed by Statistical Package for the Social Sciences (SPSS) software using statistical package version 16 (SPSS, Inc., USA). Quantitative data were expressed as mean \pm standard deviation $(X \pm S D)$. The significance of differences between groups was determined by oneway analysis of variance followed by a post hoc Tukey test. $p<0.05$ was considered statistically significant $(p<0.05)$. 


\section{Results}

\section{Serum testosterone}

The mean value of serum testosterone was significantly lower in the DOX group when compared to the control group $(0.57 \pm 0.1$ vs. $4.63 \pm 0.38 \mathrm{ng} / \mathrm{mL}$, $\mathrm{p}<$ 0.001). Serum testosterone levels were significantly higher in DOX/Gin $(1.53 \pm 0.32 \mathrm{ng} / \mathrm{mL})$ DOX/CoQ10 (1.71 $\pm 0.15 \mathrm{ng} / \mathrm{mL})$, and DOX/ Gin+CoQ10 (3.15 $\pm 0.26 \mathrm{ng} / \mathrm{mL})$ groups when compared to the DOX group $(p<0.001)$ and significantly lower when compared to the control group $(p<0.001)$. Serum testosterone level of DOX/Gin+CoQ10 was significantly higher when compared to DOX/Gin and DOX/CoQ10 $(p<0.001)$. There was no statistically significant difference in the serum testosterone level of DOX/Gin and DOX/CoQ10 groups ( $p>0.05)$ (Figure 1).

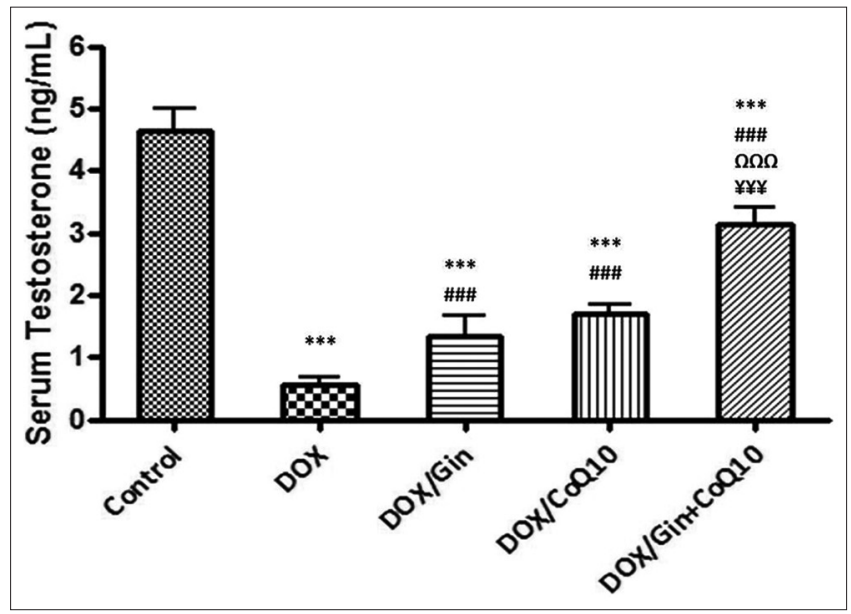

Figure 1: Serum testosterone $(\mathrm{ng} / \mathrm{mL})$ in all studied groups $\left(^{* * *}: p<0.001\right.$ vs. control group, \#\#: $p<0.001$ vs. DOX group, $\Omega$ $\Omega \Omega: p<0.001$ vs. DOX/Gin group, $¥ ¥: p<0.001$ vs. DOX/CoQ10 group). DOX: Doxorubicin, DOX/Gin: Doxorubicin/ginseng treated, DOX/CoQ10: Doxorubicin/CoQ10 treated, DOX/Gin+CoQ10: Doxorubicin/ginseng+CoQ10 treated. Data are shown as means $\pm S D$ $(n=10)$. ANOVA was used to make group comparisons

\section{Serum liver enzymes}

Regarding serum liver enzymes results, DOX group showed significantly higherALT $(168.93 \pm 11.26$ vs . $38.85 \pm 4.11 \mathrm{U} / \mathrm{L})$, AST (204.8 \pm 10.24 vs. 53.5 $\pm 4.39 \mathrm{U} / \mathrm{L}), \operatorname{ALP}(301.53 \pm 7.51$ vs. $108.87 \pm 10.78$ $\mathrm{U} / \mathrm{L})$, and GGT $(17.35 \pm 2.13$ vs. $5.03 \pm 0.65 \mathrm{U} / \mathrm{L})$ levels when compared to the control group $(p<0.001)$. Serum ALT, AST, ALP, and GGT were significantly lower in DOX/ Gin (118.5 $\pm 8.11,144.27 \pm 4.88$, $247 \pm 7.66$, and $12.8 \pm 1.26 \mathrm{U} / \mathrm{L}$, respectively), DOX/CoQ10 (120.6 \pm 13.18, $140.03 \pm 8.21,242.67$ \pm 10.39 , and $12.3 \pm 1.56 \mathrm{U} / \mathrm{L}$, respectively), and DOX/ Gin+CoQ10 (83.68 \pm 7.2, $103.75 \pm 5.72,200.37$ \pm 10.72 , and $8.37 \pm 0.497 \mathrm{U} / \mathrm{L}$, respectively) groups when compared to the DOX group $(p<0.001)$ and significantly higher than that of the control group $(p<0.001)$. There were significantly lower values of DOX/Gin+CoQ10 when compared to DOX/Gin and DOX/CoQ10 ( $p<0.001)$. However, there was insignificant difference in serum liver enzymes of DOX/ Gin and DOX/CoQ10 groups ( $p>0.05$ (Figure 2).

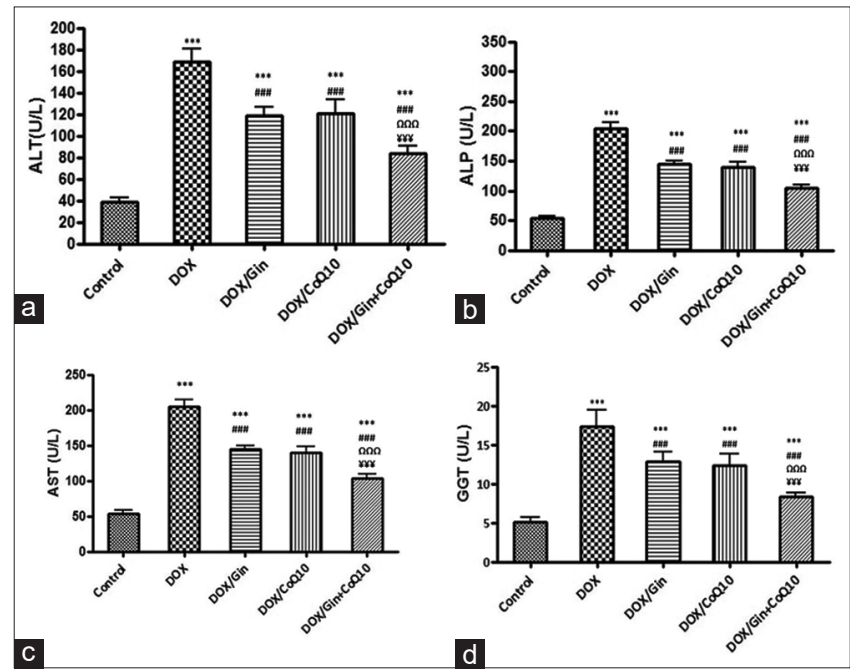

Figure 2: (a) Serum alanine transaminase (ALT) (U/L). (b) Serum alkaline phosphatase $(A L P)(U / L)$. (c) Serum aspartate transaminase (AST) (U/L). (d) Serum gamma-glutamyl transferase (GGT) (U/L), in all studied groups $\left(^{* * *}: p<0.001\right.$ vs. control group, \#\#\#: $p<0.001$ vs. DOX group, $\Omega \Omega \Omega: p<0.001$ vs. DOX/Gin group, $¥ ¥ ¥: p<0.001$ vs. DOX/CoQ10 group). DOX: Doxorubicin, DOX/Gin: Doxorubicin/ginseng treated, DOX/CoQ10: Doxorubicin/ CoQ10 treated, DOX/Gin+CoQ10: Doxorubicin/ginseng+CoQ10 treated. Data are shown as means $\pm S D(n=10)$. ANOVA was used to make group comparisons

\section{Testis and liver indices and serum lipids}

The mean values of testis and liver index were significantly lower in the DOX group when compared to the control group $(0.44 \pm 0.03$ vs. $0.75 \pm 0.04$, $2.01 \pm 0.13$ vs. $2.91 \pm 0.16$, respectively, $p<0.001$ ) Testis and liver index values were significantly higher in DOX/Gin $(0.56 \pm 0.03, p<0.001$ and $2.27 \pm 0.11$, $\mathrm{p}<0.01$, respectively), DOX/CoQ10 (0.58 \pm 0.01, $p<0.001$ and $2.25 \pm 0.11, p<0.05$, respectively), and DOX/Gin+CoQ10 groups $(0.63 \pm 0.04$ and $2.62 \pm 0.06$ [p $<0.001]$, respectively) when compared to the DOX group and significantly lower when compared to the control group ( $p<0.001$ ). Testis index value of DOX/Gin+CoQ10 was significantly higher when compared to DOX/Gin $(p<0.05)$ and insignificant difference with DOX/CoQ10 ( $p>0.05)$. The liver index value of DOX/Gin+CoQ10 was significantly higher when compared to DOX/Gin and DOX/CoQ10 ( $p<0.001)$. There was no statistically significant difference in testis and liver index values of DOX/Gin and DOX/CoQ10 groups $(p>0.05)$ (Figure 3a).

Regarding lipid profile results, DOX group showed significantly higher serum cholesterol $(158.67 \pm 7.31$ vs. $90.16 \pm 6.11 \mathrm{mg} / \mathrm{dl})$ and TG $(115.15 \pm 5.67$ vs. $40.92 \pm 4.78 \mathrm{mg} / \mathrm{dl})$ levels when compared to control group ( $p<0.001)$. Serum cholesterol and TG were significantly lower in DOX/Gin 


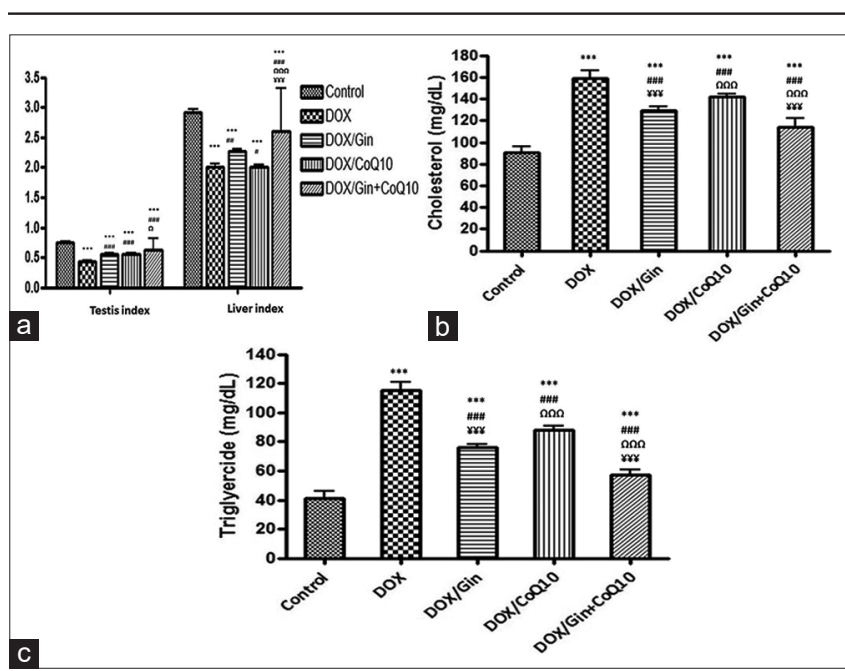

Figure 3: (a) Testis and liver indices. (b) Serum cholesterol ( $\mathrm{mg} / \mathrm{dll}$ ). (c) Serum triglyceride ( $\mathrm{mg} / \mathrm{dl})$, in all studied groups (***: $p<0.001$ vs. control group, \#: $p<0.05$ vs. DOX group, \#\#: $p<0.01$ vs. DOX group, \#\#\#: $p<0.001$ vs. DOX group, $\Omega: p<0.05$ vs. DOX/Gin group,

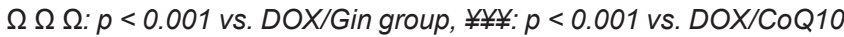
group). DOX: Doxorubicin, DOX/Gin: Doxorubicin/ginseng treated, DOX/CoQ10: Doxorubicin/ CoQ10 treated, DOX/Gin+CoQ10: Doxorubicin/ginseng + CoQ10 treated. Data are shown as means $\pm S D$ $(n=10)$. ANOVA was used to make group comparisons

$(129.67 \pm 3.07$ and $75.85 \pm 2.08 \mathrm{mg} / \mathrm{dl}$, respectively), DOX/CoQ10 $(141.98 \pm 2.54$ and $88.3 \pm 2.47 \mathrm{mg} / \mathrm{dl}$, respectively), and DOX/Gin+CoQ10 (114.17 \pm 7.78 and $57.5 \pm 3.08 \mathrm{mg} / \mathrm{dl}$, respectively) groups when compared to the DOX group $(p<0.001)$ and significantly higher when compared to the control group $(p<0.001)$. There were significantly lower values of DOX/Gin+CoQ10 when compared to DOX/Gin and DOX/CoQ10 $(p<0.05)$. There were significantly lower values of DOX/Gin group when compared with DOX/CoQ10 group $(p<0.001)$ (Figure $3 b$ and $c)$.

\section{Testicular and hepatic MDA and SOD}

The mean values of testicular and hepatic MDA were significantly higher in the DOX group when compared to the control group $(45.31 \pm 0.93$ vs. $20.83 \pm 1.65$ and $44.98 \pm 3.19$ vs. $22.1 \pm 2.05 \mathrm{nmol} / \mathrm{gm}$.tissue, respectively, $\mathrm{p}<0.001)$. However, testicular and hepatic MDA mean values were significantly lower in DOX/Gin $(36.6 \pm 2.22$ and $37.93 \pm 1.98 \mathrm{nmol} / \mathrm{gm}$.tissue, respectively), DOX/CoQ10 (38.33 \pm 1.83 and $38.99 \pm 1.74$ nmol/gm.tissue, respectively), and DOX/Gin+CoQ10 groups $(32.41 \pm 2.47$ and $31.02 \pm 1.81 \mathrm{nmol} / \mathrm{gm}$.tissue, respectively) when compared to the DOX group $(p<0.001)$ and significantly higher when compared to the control group $(p<0.001)$. Testicular and hepatic MDA mean values of DOX/Gin+CoQ10 were significantly lower when compared to DOX/Gin and DOX/CoQ10 $(p<0.001)$. There was no statistically significant difference in testicular and hepatic MDA levels of DOX/Gin and DOX/CoQ10 groups $(p>0.05)$ (Figure $4 a)$.

The mean values of testicular and hepatic SOD were significantly lower in the DOX group when compared
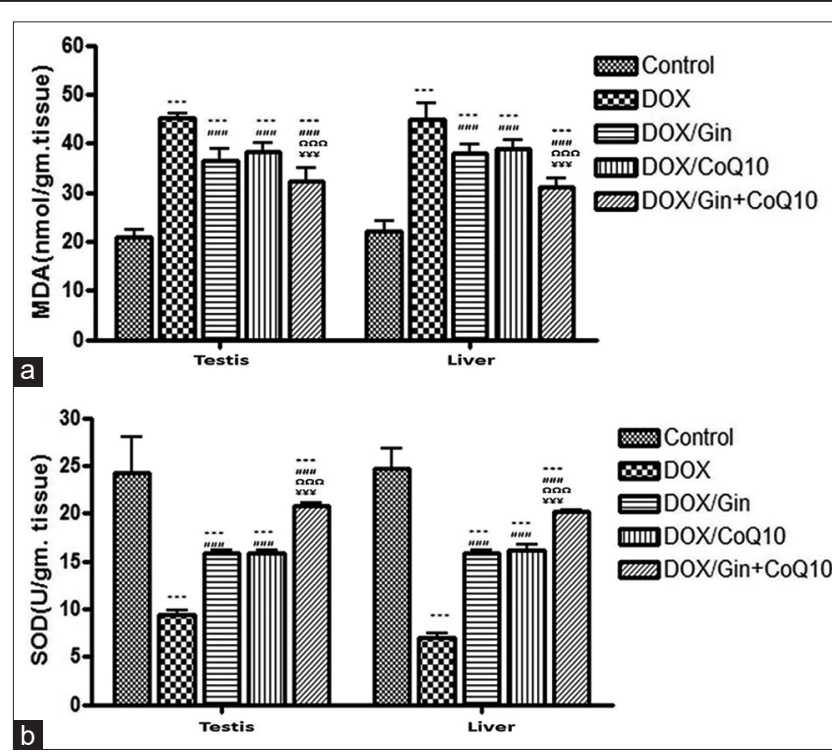

Figure 4: (a) Testicular and hepatic malondialdehyde (nmol/ gm.tissue). (b) Testicular and hepatic superoxide dismutase (U/ gm.tissue), in all studied groups $\left(^{* * *}: p<0.001\right.$ vs. control group, \#\#\#: $p<0.001$ vs. DOX group, $\Omega \Omega \Omega: p<0.001$ vs. DOX/Gin group, $¥ ¥ ¥: p<0.001$ vs. DOX/CoQ10 group). DOX: Doxorubicin, DOX/Gin: Doxorubicin/ginseng treated, DOX/CoQ10: Doxorubicin/ CoQ10 treated, DOX/Gin+CoQ10: Doxorubicin/ginseng+CoQ10 treated. Data are shown as means $\pm S D(n=10)$. ANOVA was used to make group comparisons

to the control group $(9.36 \pm 1.59$ vs. $24.25 \pm 3.81$ and $6.99 \pm 1.46$ vs. $24.7 \pm 2.14 \mathrm{U} / \mathrm{gm}$ tissue, respectively, $p<0.001)$. Testicular and hepatic SOD levels were significantly higher in DOX/Gin (15.82 \pm 0.99 and $15.83 \pm 0.95$ respectively), DOX/CoQ10 (15.82 \pm 0.92 and $16.21 \pm 1.69$, respectively), and DOX/Gin+CoQ10 groups $(20.75 \pm 1.22$ and $20.17 \pm 0.74 \mathrm{U} / \mathrm{gm}$ tissue, respectively) when compared to the DOX group $(p<0.001)$ and significantly lower when compared to the control group ( $p<0.001)$. Testicular and hepatic SOD levels of DOX/Gin+CoQ10 were significantly higher than those of DOX/Gin and DOX/CoQ10 $(p<0.001)$. There was no statistically significant difference in testicular and hepatic SOD mean values of DOX/Gin and DOX/CoQ10 groups ( $>0.05)$ (Figure $4 b)$.

\section{Serum TNF- $\alpha$, IL-6, and IL-10}

The mean values of serum TNF- $\alpha$ and IL-6 levels were significantly higher in the DOX group when compared to the control group $(56.58 \pm 3.11 \mathrm{vs} .15 .92 \pm 3.12 \mathrm{ng} / \mathrm{mL}$ and $141.67 \pm 3.98 \mathrm{vs}$. $74.58 \pm 4.57 \mathrm{Pg} / \mathrm{mL}$, respectively, $p<0.001)$. Serum TNF- $\alpha$ and IL-6 levels were significantly lower in DOX/Gin $(43.08 \pm 3.35 \mathrm{ng} / \mathrm{mL}$ and $111.98 \pm 4.83 \mathrm{Pg} / \mathrm{mL}$, respectively), DOX/CoQ10 $(43 \pm 3.35 \mathrm{ng} / \mathrm{mL}$ and $110.85 \pm 8.28$ $\mathrm{Pg} / \mathrm{mL}$, respectively), and DOX/Gin+CoQ10 groups $(33.83 \pm 4.12 \mathrm{ng} / \mathrm{mL}$ and $94.33 \pm 6.89$ $\mathrm{Pg} / \mathrm{mL}$, respectively) when compared to the DOX group $(p<0.001)$ and significantly higher when compared to the control group $(p<0.001)$. Serum TNF- $\alpha$ and IL-6 levels of DOX/Gin+CoQ10 were significantly 
lower when compared to DOX/Gin and DOX/CoQ10 $(p<0.001)$. There was no statistically significant difference in serum TNF- $\alpha$ and IL- 6 levels of DOX/Gin and DOX/CoQ10 groups ( $p>0.05$ ). However, the mean value of serum IL-10 was significantly lower in the DOX group when compared to the control group $(5.42 \pm 0.95$ vs. $17.67 \pm 1.78 \mathrm{ng} / \mathrm{mL}, p<0.001)$. Serum IL-10 was significantly higher in DOX/Gin (8.78 \pm 0.73), DOX/CoQ10 (8.67 $\pm 0.87 \mathrm{ng} \mathrm{mL})$, and DOX/ Gin+CoQ10 (12.8 $\pm 0.96 \mathrm{ng} / \mathrm{mL})$ groups when compared to the DOX group $(p<0.001)$ and significantly lower when compared to the control group $(p<0.001)$. Serum IL-10 level of DOX/Gin+CoQ10 was significantly higher when compared to DOX/Gin and DOX/CoQ10 ( $p<0.001)$. There was no statistically significant difference in the mean values of serum IL-10 level of DOX/Gin and DOX/CoQ10 groups $(p>0.05)$ (Figure 5a-c).

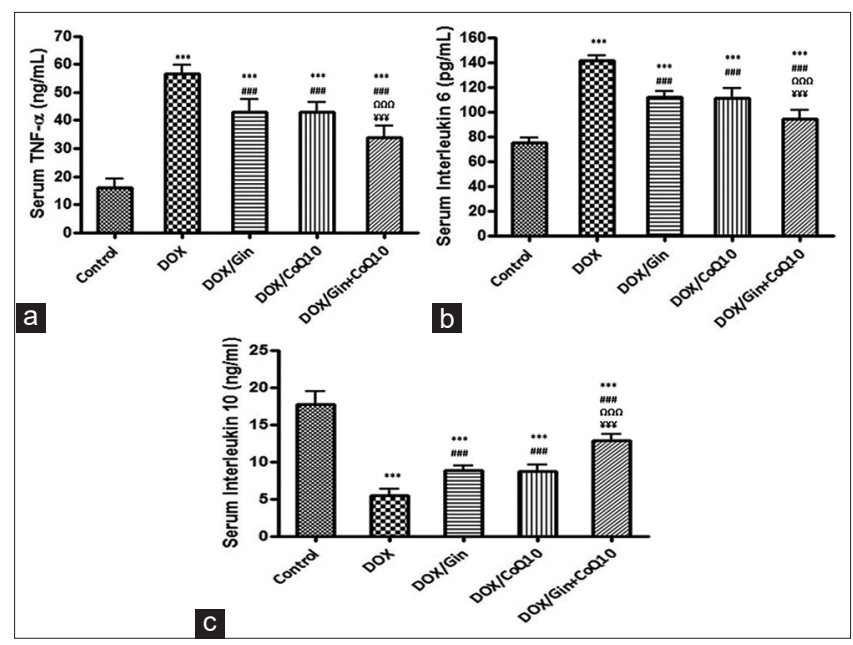

Figure 5: (a) Serum tumor necrosis factor-alpha $(n g / m L)$. (b) Serum interleukin-6 (pg/mL). (c) Serum interleukin $10(\mathrm{ng} / \mathrm{mL})$, in all studied groups (***: $p<0.001$ vs. control, \#\#: $p<0.001$ vs. DOX group,

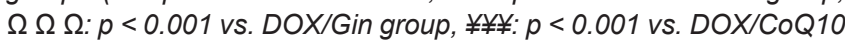
group). DOX: Doxorubicin, DOX/Gin: Doxorubicin/ginseng treated, DOX/CoQ10: Doxorubicin/ COQ10 treated, DOX/Gin+CoQ10: Doxorubicin/ginseng + CoQ10 treated. Data are shown as means $\pm S D$ $(n=10)$. ANOVA was used to make group comparisons

\section{expression}

\section{Testicular and hepatic Nrf2 gene}

Expression of testicular and hepatic Nrf2 gene in DOX group was significantly downregulated when compared to the control group $(0.107 \pm 0.013$ vs. $1 \pm 0$, $0.205 \pm 0.019$ vs. $1 \pm 0$, respectively, $p<0.001)$. However, expression of testicular and hepatic Nrf2 genes in DOX/Gin $(0.49 \pm 0.035$ and $0.598 \pm 0.011$, respectively), DOX/CoQ10 (0.413 \pm 0.055 and $0.515 \pm 0.086$, respectively), and DOX/Gin+CoQ10 (0.732 \pm 0.046 and $0.878 \pm 0.044$, respectively) groups was significantly upregulated when compared to DOX group ( $p<0.001$ ) but significantly lower than control group. Expression of testicular and hepatic Nrf2 gene in DOX/Gin+CoQ10 group was significantly upregulated when compared to DOX/Gin and DOX/CoQ10 $(p<0.05)$. Expression of testicular and hepatic Nrf2 gene in DOX/Gin was significantly upregulated when compared to DOX/CoQ10 ( $p<0.05)$ (Figure 6).

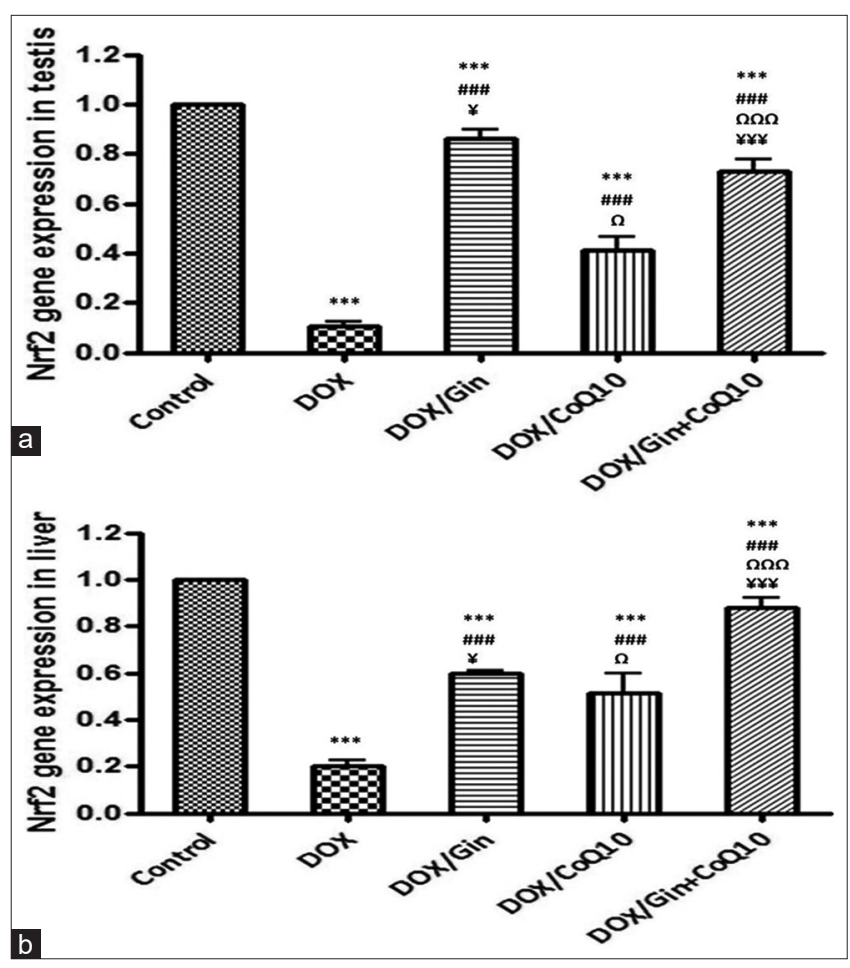

Figure 6: (a) Nuclear factor E2-related factor 2 gene expression in testis. (b) Nuclear factor E2-related factor 2 gene expression in liver, in all studied groups (***: $p<0.001$ vs. control group, \#\#\#: $p<0.001$ vs. DOX group, $\Omega: p<0.05$ vs. DOX/Gin group, $\Omega \Omega$ $\Omega: p<0.001$ vs. DOX/Gin group, $¥: p<0.05$ vs. DOX/CoQ10 group, $¥ ¥ ¥: p<0.001$ vs. DOX/CoQ10 group). DOX: Doxorubicin, DOX/Gin: Doxorubicin/ginseng treated, DOX/CoQ10: Doxorubicin/CoQ10 treated, DOX/Gin+CoQ10: Doxorubicin/ginseng+CoQ10 treated. Data are shown as means $\pm S D(n=10)$. ANOVA was used to make group comparisons

\section{Histopathological results}

Histological examination of testis tissue of the control group stained with H\&E showed rounded to oval seminiferous tubules, separated by a minimal amount of interstitial tissue containing Leydig cells, and lined by multiple layers of germinal epithelium. This germinal epithelium revealed pyramidal Sertoli cells and oval spermatogonia with darkly stained nuclei close to the basement membrane. Primary spermatocytes were the largest one seen within the seminiferous tubules. Spermatids were small cells arranged in 2-4 rows lying close to the lumen. Moreover, eosinophilic threads representing tails of the sperms were observed in the lumen of most of the tubules. Spindle-shaped myoid cells resting on the outer surface of the basement membrane were also detected (Figure 7).

Seminiferous tubules of DOX group showed loss of architecture, significant disorganization in the basal membrane and few disorganized germ cell layers associated with vacuolization, and degeneration of the 


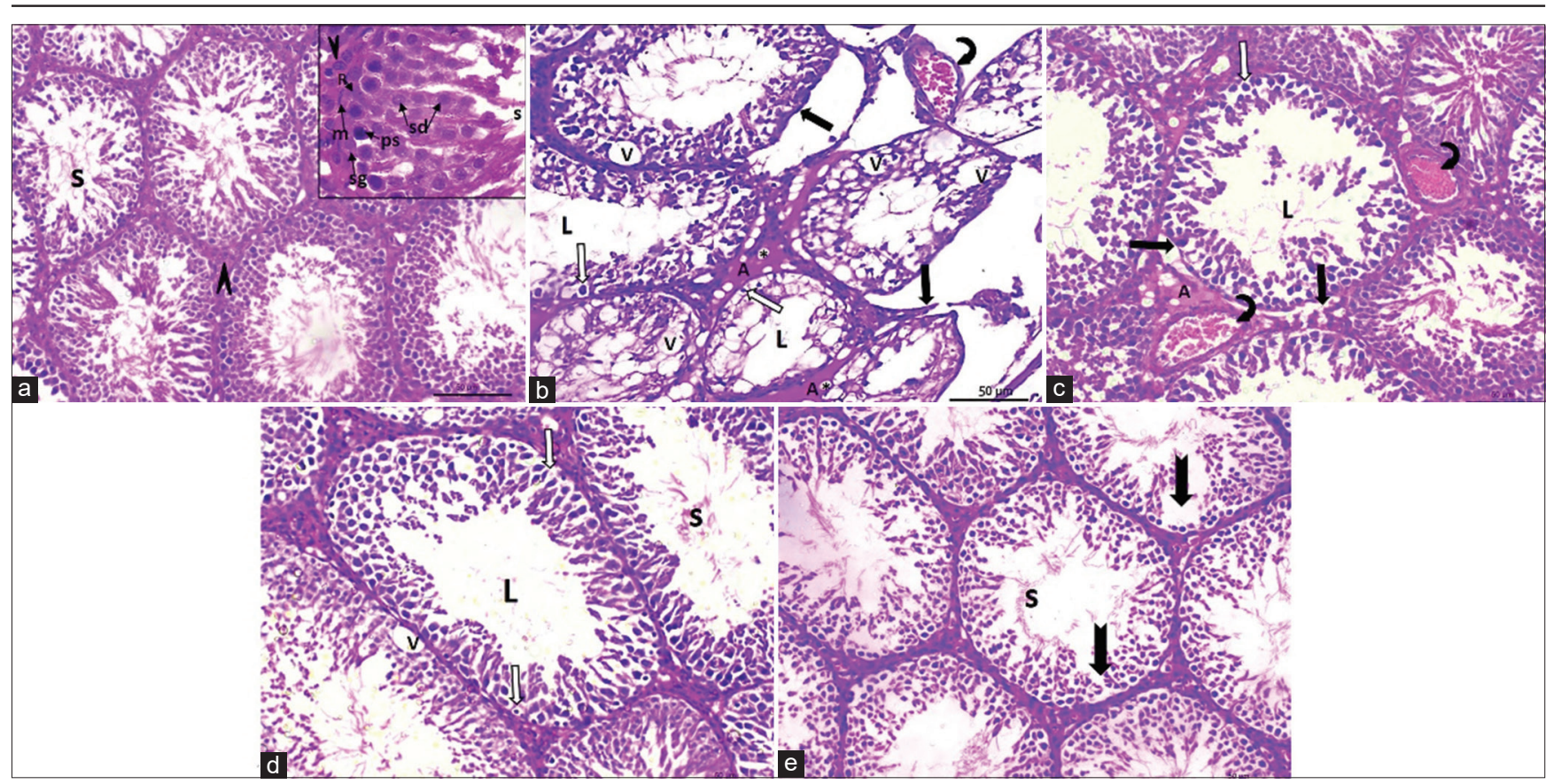

Figure 7: Representative micrographs of H\&E testicular section of all experimental groups showing (a) seminiferous tubules of control group containing different stages of spermatogenic cells; spermatogonia (sg), primary spermatocytes (ps), spermatids (sd), and the Sertoli cells (R) in between. Numerous mature spermatozoa (S) appear in the lumen. The myoid cells (m) are arranged outside the basal lamina. A rounded Leydig cells with an acidophilic cytoplasm (head arrow) are scattered between the seminiferous tubules H\&E, $\times 20$ and $\times 1000$. Seminiferous tubules of DOX group (b) showed distortion of the seminiferous tubules with few germ cells some are disorganized with deeply stained pyknotic nuclei (white arrow), others showed cytoplasmic vacuolation (V). The germ cells detached from basement membrane (black arrow). The lumen of tubules contains few spermatozoa (L). Wide intertubular space appeared containing homogenous acidophilic material (A), many vacuoles (star) and congested dilated blood vessels (curved arrow). Administration of Gin (c) revealed apparent a smaller number of pyknotic germ cells (white arrow), mild detachment from basement membrane (black arrow). The lumen of tubules contains moderate number of spermatozoa (L). Intertubular space appeared containing homogenous acidophilic material (A), less vacuoles (star) and congested dilated blood vessels (curved arrow). Administration of CoQ10 (d) resulted in amelioration of the architecture with less vacuolated germ cells (V), apparent a smaller number of pyknotic germ cells (white arrow) and few sperms (S) in the lumen (L). Combination of Gin and CoQ10 (e) induced significant improvement in the histopathological picture with loss of germ cells from some seminiferous tubules (notched arrow) (H\&E, $\times 20,50 \mu m$ scale)

lining epithelial cells. The lumen of tubules revealed few spermatozoa. The intertubular space appeared wide, contained homogenous acidophilic material, and congested dilated blood vessels. These changes were ameliorated in the groups treated with Gin or CoQ10. Moreover, the combination of Gin- and CoQ10-induced significant improvement in the histopathological results compared to the use of each of these drugs alone (Figure 7).

The control hepatic tissue showed normal large polygonal cells with prominent round nuclei and eosinophilic cytoplasm, and few spaced hepatic sinusoids arranged in-between the hepatic cords. The sinusoids were lined by flat endothelial cells. DOX group hepatic sections showed dissolution of hepatic cords, which appeared as empty vacuoles with shrunken, irregular, and darkly stained nuclei. Furthermore, there was a higher tendency for liver fibrosis manifested by the presence of many spots of focal cellular aggregations (Figure 8).

The DOX/Gin treated group showed mild cloudy swelling and inflammation. Hepatic lesions were improved in animals, which received Dox and CoQ10 treatment; whereas the hepatic tissues in the DOX/ Gin+CoQ10 treated group were apparently normal (Figure 8).

\section{Immunohistochemical and morphometric} results

Administration of DOX was associated with a significant increase in area \% of the caspases- 3 immunohistochemical staining (59.6 \pm 8.53 vs. $0.80 \pm 0.86, p<0.001)$ compared to the control group. The treatment with Gin, CoQ10, or Gin+CoQ10 showed significantly lower caspases-3 area \% of immunohistochemical staining (34.00 \pm 7.62 , $24.00 \pm 3.67$, and $13.40 \pm 3.85$, respectively, $p<0.001)$ compared with the DOX group. Moreover, the Gin+CoQ10 combination induced a significant reduction in the caspase-3 immunoreactivity compared to the use of each of these drugs alone (Figure 9).

The liver sections of the Dox group showed a significant increase in area \% of positive immune reaction for caspase-3-positive cells as compared to the control group $(69.00 \pm 5.43$ vs. $0.60 \pm 0.55$, $\mathrm{p}<0.001)$. DOX/Gin, DOX/CoQ10 treated as well as DOX/Gin+CoQ10 treated groups showed a significant decrease in area \% of positive immune reaction for caspase-3-positive cells as compared to the DOX group $(33.80 \pm 8.93,21.80 \pm 4.32$, and $14.80 \pm 3.70$, $\mathrm{p}<0.001$, respectively) but Gin+CoQ10 combination induced a significant reduction in the caspase-3 
immunoreactivity compared to the use of each of these drugs alone (Figure 9).

\section{Discussion}

Although DOX is a successful cancer chemotherapeutic, side effects limit the clinical utility of DOX-based therapy, including male infertility [4] and hepatotoxicity [3]. The results of the DOX group revealed a significant decrease in serum testosterone and testis index value when compared with the control group. These results were in accordance with previous reported results [4], [29]. The antineoplastic agents can disturb Leydig cells directly [30]. Thus, the reduction in circulating testosterone is supposed to be resulting from a direct poisonous effect of DOX on the Leydig cells. A marked decrease in testis index value by DOX can be result of reduced number of germ cells, atrophy of Leydig cells, and lower rate of spermatogenesis, as

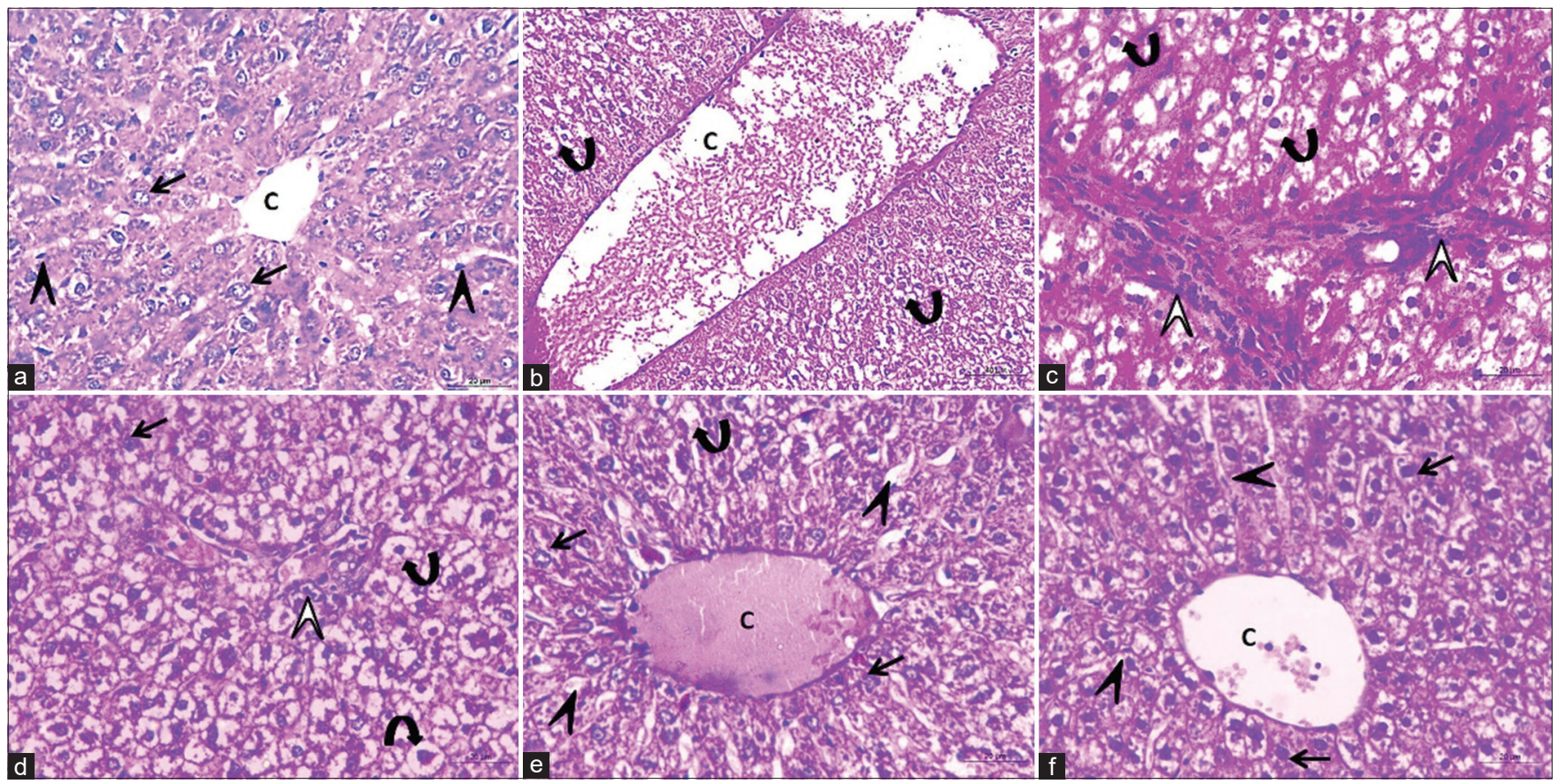

Figure 8: Representative micrographs of H\&E liver sections of different experimental groups showing normal hepatic lobular architecture showing the central vein (C) at the center of classic hepatic lobule and cords of hepatocytes with large rounded vesicular nuclei (arrows) radiating from it and separated by the blood sinusoids (arrowheads). The sinusoids were lined by flat endothelial cells. DOX group (b and $c$ ), dilated congested central vein (C) could be detected. The hepatic sections showing dissolution of hepatic cords, which appeared as empty vacuoles with shrunken, irregular, and darkly stained nuclei (curved arrows). Many spots of focal cellular aggregations (white arrowheads) could be detected. The DOX/Gin treated group (D) showing hepatocytes appeared as empty vacuoles with shrunken, irregular, and darkly stained nuclei (curved arrows), spots of focal cellular aggregations (white arrowheads), and normal hepatocytes (arrow). Animals, which received Dox and CoQ10 treatment showing normal hepatocytes (arrows) and blood sinusoids (black arrowheads), degenerated hepatocytes (curved arrow) and congested dilated central vein (C); whereas the hepatic tissues in the DOX/Gin+CoQ10 treated group were apparently as control group except for dilated central vein (C). (a, c, d, e and f; Scale bar $20 \mu \mathrm{m}$, B; scale bar $40 \mu \mathrm{m}$ )

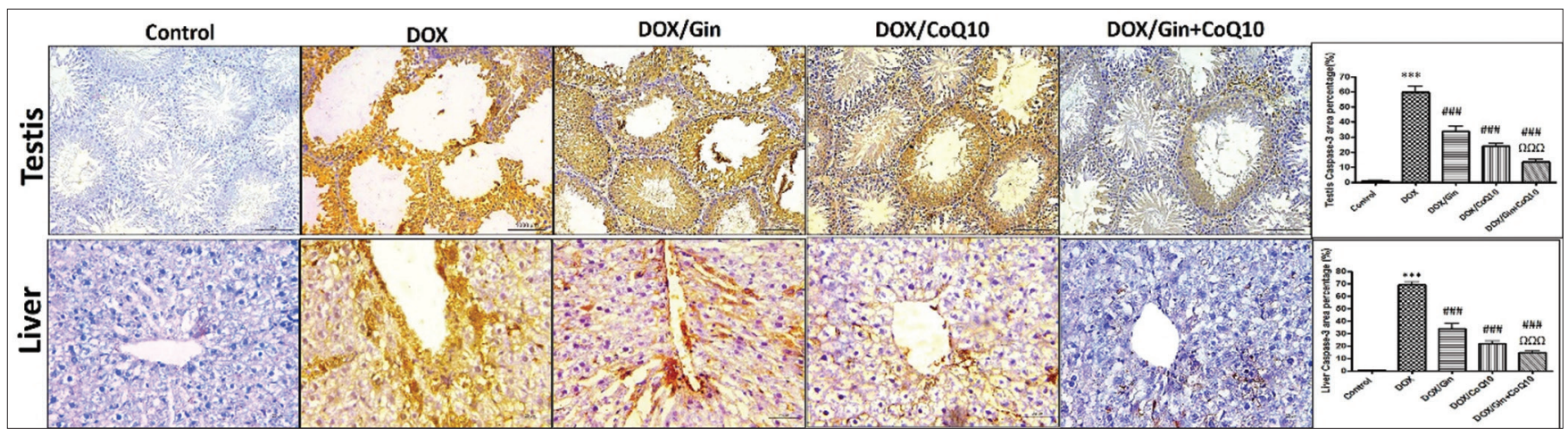

Figure 9: Representative caspase-3 staining of rat testis and liver of different groups: DOX administration upregulated expression of caspase-3 immunoexpressing in both testis and liver tissues, ${ }^{* * *} p<0.001$ versus control group. This increase was significantly decreased in DOX/Gin, DOX/CoQ10, and DOX/Gin+CoQ10 groups; \#\# $p<0.001$ versus DOX group. Scale bar $20 \mu M, \times 400$. DOX: Doxorubicin, DOX/Gin: Doxorubicin/ ginseng treated, DOX/CoQ10: Doxorubicin/CoQ10 treated, DOX/Gin+CoQ10: Doxorubicin/ginseng+CoQ10 treated 
confirmed by our histological findings which showed that the seminiferous tubules of DOX group showed loss of architecture, significant disorganization in the basal membrane, and few disorganized germ cell layers associated with vacuolization, and degeneration of the lining epithelial cells. This is in agreement with previous reported studies [26].

The leakage of hepatocellular enzymes is used as a hepatotoxicity marker. The results of the DOX group revealed a significant increase in serum liver enzymes (ALT, AST, ALP, and GGT) and a decrease in liver index value when compared with the control group, following our results previous reported studies [3], [31]. The DOX prompted hepatotoxicity can be attributed to free radical-induced oxidative stress mechanism during hepatic drug metabolism [32]. This evokes ROS initiated lipid peroxidation favoring hepatocyte damage and creating ALT and AST spillage into the serum. This was confirmed by our histological results of liver, in agreement with previous results [31].

However, rats treated with ginseng revealed a significant increase in serum testosterone and testis index value when compared with the DOX group, and this is in accordance with previous results [33]. Ginseng has potent effects on sexual function and could relieve senile testicular dysfunction [34]. In addition, ginseng rescued testicular impairment in aged rats through regulation of the oxidative defense systems [35]. Ginseng improved spermatogenesis in experimental models of testicular dysfunction [36]. Furthermore, our histological results revealed amelioration in changes induced by DOX in rats treated by ginseng.

Treatment with ginseng revealed, also, a significant decrease in serum liver enzymes and increase in liver index value when compared with the DOX group in accordance with our results previous reported study [24]. Similar previous studies demonstrated that ginseng extract had antioxidant activity and acted as a free radical scavenger [37], [38]. It has been reported that ginsenosides are responsible for its hepatoprotective effect by destroying lipid peroxyl radicals and ROS [37] and this was confirmed by our histological results.

Treatment of rats with CoQ10 revealed a significant increase in serum testosterone and testis index value when compared with the DOX group. Oda et al. stated that supplementation of CoQ10 to oxytetracyclinetreated rats showed elevated serum levels of testosterone and restored relative testis weight [25]. Furthermore, CoQ10 as an antioxidant suppressed lipid peroxidation in testis. Similarly, oral CoQ10 induced an increase in SOD activity in infertile men [39].

Treatment with CoQ10 revealed also, significant decrease in serum liver enzymes and increase in liver index value when compared with the DOX group. These results are in accordance with previous reported results [40], and this was confirmed by our histological results.
The results of the Dox group revealed significant elevation of serum cholesterol and TG when compared with the control group. These results have been in accordance with previous reported results [41]. However, rats treated with ginseng revealed a significant decrease in serum cholesterol and TG levels when compared with DOX group. Hafez et al. revealed that the increased levels of TGs and total cholesterol were restored to their normal values with carbon tetrachloride $(\mathrm{CCl} 4)+$ ginseng [24]. Ginseng products are responsible for its hypolipidemic effect [42]. Treatment with CoQ10 revealed a significant decrease in serum cholesterol and TG when compared with the DOX group and a significant increase when compared with DOX/Gin group. The improvement in the hypolipidemic effect of atorvastatin by CoQ10 has already been reported in Guinea pigs [43].

Oxidative stress plays an essential role in DOX-induced toxicity through the formation of ROS [7]. The results of the Dox group revealed significant elevation of testicular and hepatic MDA levels and a significant decrease in testicular and hepatic SOD when compared with the control group. These results are in accordance with previous reported studies [29], [31]. It has been demonstrated that oxygen radical-induced damage of lipids in the membrane is the key factor for DOX-induced toxicity [44]. The adverse effects of DOX result mainly from its essential tendency to produce free radicals and block antioxidant enzymes in various tissues [45]. However, rats treated with ginseng revealed a significant decrease in testicular and hepatic MDA levels and a significant increase in testicular and hepatic SOD when compared with the DOX group. Ginseng has potent antioxidant effects and increases the protein expression level of antioxidants in rats [46]. Ginseng prevented severe testicular toxicity induced by 2,3,7,8-tetrachlorodibenzo-p-dioxin in rats through its antioxidant activity [47]. It has been reported that ginsenosides are responsible for its hepatoprotective effect by destroying lipid peroxyl radicals and ROS [48].

Treatment with CoQ10 revealed a significant decrease in testicular and hepatic MDA levels and a significant increase in testicular and hepatic SOD when compared with the DOX group. These results are accordance with the previous study [49]. Saleh et al. concluded that the supplementation of CoQ10 significantly ameliorated liver function and hepatic antioxidant defense capacity and attenuated ROS levels [49]. Studies have shown that the CoQ10 has free radical scavenging activities and liver injury reducing properties [50]. CoQ10 is a powerful antioxidant. CoQ10 inhibits the generation of ROS [51] and scavenges lipid peroxidation products during free radical reactions [52]. There was no significant difference between DOX/Gin and DOX/CoQ10 groups.

The results of the Dox group revealed significant elevation of pro-inflammatory markers serum TNF- $\alpha$ and IL- 6 levels and a significant decrease of 
anti-inflammatory marker serum IL-10 when compared with the control group. These results are in accordance with previous reported studies [53]. DOX exposure activates the expression of NF- $\mathrm{KB}$ and nucleotide-binding oligomerization domain (NOD)-like receptor protein 3 (NLRP3) inflammasome which, in turn, releases proinflammatory mediator including TNF- $\alpha$ [11]. However, treatment with ginseng revealed a significant decrease in serum TNF- $\alpha$ and interleukin- 6 levels and an increase of serum IL-10 levels when compared with the DOX group. Hafez et al. revealed that ginseng extract increased the expression of IL-10, in CCl4-induced liver injury [24].

Treatment with CoQ10 revealed a significant decrease in serum TNF- $\alpha$ and IL- 6 levels and a significant increase of serum IL-10 levels of DOX/CoQ10 when compared with the DOX group. Following our results, Saleh et al. reported that supplementation of CoQ10 significantly ameliorated liver function and the production of pro-inflammatory cytokines [49]. CoQ10 exhibits anti-inflammatory properties by reducing the release of pro-inflammatory cytokines during inflammatory injury [54], [55]. There was no statistically significant difference in serum TNF- $\alpha$ and IL- 6 levels of DOX/Gin and DOX/CoQ10 groups.

In our results, the DOX/Gin+CoQ10 group showed significant improvement in all measured biochemical parameters and testis and liver indices when compared with DOX, DOX/Gin, and DOX/CoQ10 groups. This attributed to the potent effects of both ginseng and CoQ10 through synergistic properties.

The real-time PCR results for the Nrf2 gene demonstrated a significant downregulation of the expression of testicular and hepatic Nrf2 in DOX group when compared with the control group. These results have been in accordance with previous reported studies [31]. DOX hepatic damage may likewise lay on lessened hepatic Nrf2 protein expression and elevated MDA level favoring oxidative stress with hepatocyte apoptosis. These mechanisms were initially proposed to be part of the downregulation of hepatic Nrf2 expression. First, reduced glutathione can react with cysteine residues in proteins to form disulfides and this chemical process is known as S-glutathionylation [56]. Curiously, S-glutathionylation can modulate Nrf2 gene expression [57]. Nrf2 has been expressed in the control group which can be attributed to the fact that even in normal cells, ROS are produced but in a controlled fashion to help in different physiological processes within the cell [58].

Treatment of the DOX group by ginseng revealed significant upregulation of testicular and hepatic Nrf2 gene activity when compared with the DOX group. Ning et al. revealed that ginseng upregulated the protein expression of Nrf2 which was decreased in the $\mathrm{CCl}_{4}$ group, suggesting that ginseng enhanced the antioxidant ability through activation of the Nrf2 signaling pathway [59].
Treatment of the DOX group by CoQ10 revealed significant upregulation of testicular and hepatic Nrf2 gene expression of DOX/CoQ10 when compared with the DOX group. However, it was significantly downregulated when compared to DOX/ Gin group. Tarry-Adkins et al. revealed that $\mathrm{CoQ}_{10}$ may exert antifibrotic effects through the activation of the Nrf2/Nrf2/ARE pathway [60]. The antioxidant genes involved in the Nrf2/ARE pathway were increased by $\mathrm{CoQ}_{10}$ supplementation [61]. The combined group shows significant upregulation of Nrf2 gene expression when compared with other treated groups.

Our results revealed that administration of DOX was associated with a significant increase in the caspases-3 immunohistochemical staining of testis and liver compared to the control group. This finding was consistent with previous reported studies [62], [63]. The treatment with ginseng showed a significantly decrease of caspases-3 immunohistochemical staining of testis and liver compared with the DOX group. There results in accordance with previous reported results [63]. The treatment with CoQ10 also showed significantly lower values of caspases-3 immunohistochemical staining of testis and liver compared with the DOX group. The previous studies showed the therapeutic effects of CoQ10 on metabolic stress by inhibition of apoptosis in hepatocytes [64]. Gin+CoQ10 group showed significantly lower expression of caspases-3 immunohistochemical staining compared with the DOX group.

\section{Conclusion}

DOX has many toxic adverse effects in organs, such as liver and testis. The mechanisms behind DOX-induced cytotoxicity are complex and continue to be not fully understood. To the best of our knowledge, this is first study elucidating the potential effects of ginseng combined with $\mathrm{CoQ}_{10}$ on DOXinduced toxicity. Based on our biochemical, molecular, and immunohistochemical findings, we believe that ginseng and $C_{0} Q_{10}$ have valuable therapeutic effects on DOX-induced toxicity through upregulation of Nrf2 gene expression, inhibition of apoptosis, antioxidant, anti-inflammatory, and hypolipidemic effects.

\section{References}

1. Markham MJ, Wachter K, Agarwal N, Bertagnolli MM, Chang SM Dale W, et al. Clinical cancer advances 2020: Annual report on progress against cancer from the American society of clinical oncology. J Clin Oncol. 2020;38(10):1081-101. https://doi. org/10.1200/jco.19.03141 


\section{PMid:32013670}

2. Podyacheva EY, Kushnareva EA, Karpov AA, Toropova YG Analysis of models of doxorubicin-induced cardiomyopathy in rats and mice. A modern view from the perspective of the pathophysiologist and the clinician. Front Pharmacol. 2021;3(12):670479. https://doi.org/10.3389/fphar.2021.670479 PMid:34149423

3. Afsar T, Razak S, Almajwal A. Effect of Acacia hydaspica R. Parker extract on lipid peroxidation, antioxidant status, liver function test and histopathology in doxorubicin treated rats. Lipids Health Dis. 2019;18(1):126. https://doi.org/10.1186/ s12944-019-1051-2

PMid:31142345

4. Ujah GA, Nna VU, Suleiman JB, Eleazu C, Nwokocha C, Rebene JA, et al. Tert-butylhydroquinone attenuates doxorubicin-induced dysregulation of testicular cytoprotective and steroidogenic genes, and improves spermatogenesis in rats. Sci Rep 2021;11:5522. https://doi.org/10.1038/ s41598-021-85026-7

5. Hinkley JM, Morton AB, Ichinoseki-Sekine N, Huertas AM, Smuder AJ. Exercise training prevents doxorubicininduced mitochondrial dysfunction of the liver. Med Sci Sports Exerc. 2019;51(6):1106-15. https://doi.org/10.1249/ mss. 0000000000001887 PMid:30629044

6. Hozayen WG. Effect of hesperidin and rutin on doxorubicin induced testicular toxicity in male rats. Int J Food Nutr Sci. 2012;1:31-42.

7. Arunachalam S, Meeran MF, Azimullah S, Sharma C, Goyal SN, Ojha S. Nerolidol attenuates oxidative stress, inflammation, and apoptosis by modulating Nrf2/MAPK signaling pathways in doxorubicin-induced acute cardiotoxicity in rats. Antioxidants. 2021;10(6):984. https://doi.org/10.3390/antiox10060984

8. Boettler $U$, Volz N, Teller N, Haupt LM, Bakuradze T, Eisenbrand G, et al. Induction of antioxidative Nrf2 gene transcription by coffee in humans: Depending on genotype? Mol Biol Rep. 2012;39(6):7155-62. https://doi.org/10.1007/ s11033-012-1547-6

PMid:22314914

9. Das J, Ghosh J, Roy A, Sil PC. Mangiferin exerts hepatoprotective activity against D-galactosamine induced acute toxicity and oxidative/nitrosative stress via Nrf2-NFkappaB pathways. Toxicol Appl Pharmacol. 2012;260(1):35-47. https://doi. org/10.1016/j.taap.2012.01.015

PMid:22310181

10. Wu S, Yue Y, Tian H, Li Z, Li X, He W, et al. Carthamus red from Carthamus tinctorius $\mathrm{L}$. exerts antioxidant and hepatoprotective effect against $\mathrm{CCl}(4)$-induced liver damage in rats via the Nrf2 pathway. J Ethnopharmacol. 2013;148(2):570-8. https://doi. org/10.1016/j.jep.2013.04.054 PMid:23684718

11. Abd El-Aziz TA, Mohamed RH, Pasha HF, Abdel-Aziz HR. Catechin protects against oxidative stress and inflammatory mediated cardiotoxicity in adriamycin-treated rats. Clin Exp Med. 2012;12(4):233-40. https://doi.org/10.1007/s10238-011-0165-2 PMid:22080234

12. Malekinejad $\mathrm{H}$, Janbaz-Acyabar $\mathrm{H}$, Razi $\mathrm{M}$, Varasteh $\mathrm{S}$. Preventive and protective effects of silymarin on doxorubicininduced testicular damages correlate with changes in c-myc gene expression. Phytomedicine. 2012;19(12):1077-84. https:// doi.org/10.1016/j.phymed.2012.06.011 PMid:22819302

13. Gray SL, Lackey BR, Boone WR. Effects of Panax ginseng, zearalenol, and estradiol on sperm function. J Ginseng Res. 2016;40(3):251-9. https://doi.org/10.1016/j.jgr.2015.08.004 PMid:27616901
14. Rahim SA. Role of Panax ginseng as an antioxidant and hepatoprotective after liver toxicity caused by flutamide in adult male rats. SRP 2020;11(6):449-58

15. Huang YC, Chen CT, Chen SC, Lai PH, Liang HC, Chang $Y$, et al. A natural compound (ginsenoside $\mathrm{Re}$ ) isolated from panax ginseng as a novel angiogenic agent for tissue regeneration. Pharm Res. 2005;22(4):636-46. https://doi.org/10.1007/ s11095-005-2500-3 PMid:15846472

16. El-Demerdash FM, El-Magd MA, El-Sayed RA. Panax ginseng modulates oxidative stress, DNA damage, apoptosis, and inflammations induced by silicon dioxide nanoparticles in rats. Environ Toxicol. 2021;36(7):1362-74. https://doi.org/10.1002/ tox.23132

PMid:33749107

17. Kwak YS, Kyung JS, Kim JS, Cho JY, Rhee MH Antihyperlipidemic effects of red ginseng acidic polysaccharides from Korean red Ginseng. Biol Pharm Bull. 2010;33(3):468-72. https://doi.org/10.1248/bpb.33.468 PMid:20190411

18. Lamia SS, Emran T, Rikta JK, Chowdhury NI, Sarker M, Jain P, et al. Coenzyme Q10 and silymarin reduce CCl4-induced oxidative stress and liver and kidney injury in ovariectomized rats-implications for protective therapy in chronic liver and kidney diseases. Pathophysiology. 2021;28:50-63. https://doi. org/10.3390/pathophysiology28010005

19. Chen HH, Yeh TC, Cheng PW, Ho WY, Ho CY, Lai CC, et al. Antihypertensive potential of coenzyme Q10 via free radical scavenging and enhanced Akt-nNOS signaling in the nucleus Tractus solitarii in rats. Mol Nutr Food Res. 2019;63(6):e1801042. https://doi.org/10.1002/mnfr.201801042 PMid:30668894

20. Mohamed HA, Said RS. Coenzyme Q10 attenuates inflammation and fibrosis implicated in radiation enteropathy through suppression of NF-kB/TGF- $\beta / M M P-9$ pathways. Int Immunopharmacol. 2021;92:107347. https://doi.org/10.1016/j. intimp.2020.107347

PMid:33418245

21. Pala R, Orhan C, Tuzcu M, Sahin N, Ali S, Cinar V, et al. Coenzyme Q10 supplementation modulates NFKB and Nrf2 pathways in exer-cise training. J Sports Sci Med. 2016;15(1):196-203.

PMid:26957943

22. El-Sheikh AA, Morsy MA, Mahmoud MM, Rifaai RA Abdelrahman AM. Effect of coenzyme-Q10 on doxorubicininduced nephrotoxicity in rats. Adv Pharmacol Sci. 2012;2012:981461. https://doi.org/10.1155/2012/981461 PMid:23346106

23. Omobowale TO, Oyagbemi AA, Ajufo UE, Adejumobi OA, OlaDavies OE, Adedapo AA et al. Ameliorative effect of gallic acid in doxorubicin-induced hepatotoxicity in wistar rats through antioxidant defense system. J Diet Suppl. 2018;15(2):183-96. https://doi.org/10.1080/19390211.2017.1335822 PMid:28718673

24. Hafez MM, Hamed SS, El-Khadragy MF, Hassan ZK, Al Rejaie SS, Sayed-Ahmed MM et al. Effect of ginseng extract on the TGF- $\beta 1$ signaling pathway in CCl4-induced liver fibrosis in rats. BMC Complement Altern Med. 2017;17(1):45. https://doi. org/10.1186/s12906-016-1507-0 PMid:28086769

25. Oda SS, Waheeb RS, El-Maddawy ZK. Potential efficacy of coenzyme Q10 against oxytetracycline-induced hepatorenal and reproductive toxicity in male rats. J Appl Pharm Sci. 2018;8(1):98-107. https://doi.org/10.7324/japs.2018.8115

26. Farsani BE, Karimi S, Mansouri E. Pravastatin attenuates testicular damage induced by doxorubicin a stereological and histopatological study. J Basic Clin Physiol Pharmacol. 
2018;30(1):103-9. https://doi.org/10.1515/jbcpp-2018-0073 PMid:30530881

27. Dorak M. Real-time PCR. Clin Chem 2018;50:1680-2.

28. Bancroft JD, Layton C. The hematoxylin and eosin, connective and mesenchymal tissues with their stains. In: Suvarna SK, Layton C, Bancroft JD, editors. Bancroft's Theory and Practice of Histological Techniques. $7^{\text {th }}$ ed. Philadelphia, PA: Churchill Livingstone; 2013. p. 173-212. https://doi.org/10.1016/ b978-0-7020-4226-3.00011-1

29. Badkoobeh P, Parivar K, Kalantar SM, Hosseini SD, Salabat A. Effect of nano-zinc oxide on doxorubicin induced oxidative stress and sperm disorders in adult male Wistar rats. Iran $\mathrm{J}$ Reprod Med. 2013;11(5):355-64.

PMid:24639766

30. Hamadouche AN, Slimani M, Merad-Boudia B, Zaoui C Reproductive toxicity of lead acetate in adult male rats. Am J Sci Res. 2009;3:38-50

31. Barakat BM, Ahmed HI, Bahr HI, Elbahaie AM. Protective effect of boswellic acids against doxorubicin-induced hepatotoxicity: Impact on Nrf2/HO-1 defense pathway. Oxid Med Cell Longev. 2018;2018:8296451. https://doi.org/10.1155/2018/8296451 PMid:29541348

32. Neilan TG, Blake SL, Ichinose F, Raher MJ, Buys ES, Jassal DS, et al. Disruption of nitric oxide synthase 3 protects against the cardiac injury, dysfunction, and mortality induced by doxorubicin. Circulation. 2007;116(5):506-14. https://doi. org/10.1161/circulationaha.106.652339 PMid:17638931

33. Kopalli SR, Cha K, Lee S, Ryu J, Hwang S, Jeong M, et al. Pectinase-treated Panax ginseng protects against chronic intermittent heat stress-induced testicular damage by modulating hormonal and spermatogenesis-related molecular expression in rats. J Ginseng Res. 2017;41(4):578-88. https:// doi.org/10.1016/j.jgr.2016.12.001

PMid:29021707

34. Hwang SY, Sohn SH, Wee JJ, Yang JB, Kyung JS, Kwak YS, et al. Panax ginseng improves senile testicular function in rats. J Ginseng Res. 2010;34:327-35. https://doi.org/10.5142/ jgr.2010.34.4.327

35. Won YJ, Kim BK, Shin YK, Jung SH, Yoo SK, Hwang SY, et al. Pectinase-treated Panax ginseng extract (GINST) rescues testicular dysfunction in aged rats via redox-modulating proteins. Exp Gerontol. 2014;53:57-66. https://doi.org/10.1016/j. exger.2014.02.012

PMid:24594315

36. Kopalli SR, Hwang SY, Won YJ, Kim SW, Cha KM, Han CK, et al. Korean red ginseng extract rejuvenates testicular ineffectiveness and sperm maturation process in aged rats by regulating redox proteins and oxidative defense mechanisms. Exp Gerontol. 2015;69:94-102. https://doi.org/10.1016/j. exger.2015.05.004

PMid:25980653

37. Kitts DD, Wijewickreme AN, Hu C. Antioxidant properties of a north american ginseng extract. Mol Cell Biochem. 2000;203(1-2):1-10.

PMid: 10724326

38. Kim HJ, Chun YJ, Park JD, Kim SI, Roh JK, Jeong TC. Protection of rat liver microsomes against carbon tetrachloride-induced lipid peroxidation by red ginseng saponin through cytochrome P450 inhibition. Planta Med. 1997;63(5):415-8. https://doi. org/10.1055/s-2006-957724

PMid:9342944

39. Safarinejad MR, Safarinejad S, Shafiei N, Safarinejad S. Effects of the reduced form of coenzyme Q10 (ubiquinol) on semen parameters in men with idiopathic infertility:
A double-blind, placebo controlled, randomized study. J Urol. 2012;188(2):526-31. https://doi.org/10.1016/j.juro.2013.01.086 PMid:22704112

40. Mustafa MN, El-Awdan SA, Hegazy GA, Abdel Jaleel GA Prophylactic role of coenzyme Q10 and Cynara scolymus $\mathrm{L}$ on doxorubicin-induced toxicity in rats. Biochemical and immunohistochemical study. Indian J Pharmacol. 2015;47(6):649-56. https://doi.org/10.4103/0253-7613.169588 PMid:26729958

41. Geetha A, Catherine J, Sankar R, Devi CS. Lipids and lipoprotein profile in doxorubicin treated rats: Influence of alpha-tocopherol administration. Indian J Exp Biol. 1990;28(11):1071-4. PMid:2283173

42. Kim HJ, Lee SG, Chae IG, Kim MJ, Im NK, Yu MH, et al Antioxidant effects of fermented red ginseng extracts in streptozotocin-induced diabetic rats. J Ginseng Res. 2011;35(2):129-37. https://doi.org/10.5142/jgr.2011.35.2.129 PMid:23717054

43. Kang MS, Yang HM, Kang JY, Ryou SH, Kang JS. Effect of coenzyme Q10 and Ardisia japonica Blume on plasma and liver lipids, platelet aggregation, and erythrocyte $\mathrm{Na}$ efflux channels in simvastatin-treated guinea pigs. Nutr Res Pract. 2012;6(5):414-20. https://doi.org/10.4162/nrp.2012.6.5.414 PMid:23198020

44. Abdel-Wahab MH, El-Mahdy MA, Abd-Ellah MF, Helal GK, Khalifa F, Hamadaa FM. Influence of pcoumaric acid on doxorubicin-induced oxidative stress in rat's heart. Pharmacol Res. 2003;48(5):461-5. https://doi.org/10.1016/ s1043-6618(03)00214-7 PMid:12967591

45. Yeh YC, Liu TJ, Wang LC, Lee HW, Ting CT. A standardized extract of Ginkgo biloba suppresses doxorubicin-induced oxidative stress and p53-mediated mitochondrial apoptosis in rat testes. $\mathrm{Br} \mathrm{J}$ Pharmacol. 2009;156(1):48-61. https://doi. org/10.1111/j.1476-5381.2008.00042.x

PMid:19133991

46. Ramesh T, Kim SW, Sung JH, Hwang SY, Sohn SH, Yoo SK et al. Effect of fermented Panax ginseng extract (GINST) on oxidative stress and antioxidant activities in major organs of aged rats. Exp Gerontol. 2012;47(1):77-84. https://doi. org/10.1016/j.exger.2011.10.007 PMid:22075532

47. Lee JH, Sul D, Oh E, Jung W, Hwang KW, Hwang TS, et al. Panax ginseng effects on DNA damage, CYP1A1 expression and histopathological changes in testes of rats exposed to 2,3,7,8-tetrachlorodibenzo-p-dioxin. Food Chem Toxicol. 2007;45(11):2237-44. https://doi.org/10.1016/j.fct.2007.05.019 PMid: 17624648

48. Kitts DD, Hu C. Efficacy and safety of ginseng. Public Health Nutr. 2000;3(4A):473-85. https://doi.org/10.1017/ s1368980000000550 PMid:11276295

49. Saleh AA, Shahin MI, Kelada NA. Hepatoprotective effect of taurine and coenzyme Q10 and their combination against acrylamide-induced oxidative stress in rats. Trop J Pharm Res. 2017;16(8):1849-55. https://doi.org/10.4314/tjpr.v16i8.14

50. Laredj LN, Licitra F, Puccio HM. The molecular genetics of coenzyme $Q$ biosynthesis in health and disease. Biochimie. 2014;100:78-87. https://doi.org/10.1016/j.biochi.2013.12.006 PMid:24355204

51. Sohet FM, NeyrinckAM, Pachikian BD, de Backer FC, Bindels LB Niklowitz P, et al. Coenzyme Q10 supplementation lowers hepatic oxidative stress and inflammation associated with diet-induced obesity in mice. Biochem Pharmacol. 2009;78(11):1391-400. https://doi.org/10.1016/j.bcp.2009.07.008 
PMid: 19632207

52. Tsuneki H, Sekizaki N, Suzuki T, Kobayashi S, Wada T, Okamoto T, et al. Coenzyme Q10 prevents high glucose-induced oxidative stress in human umbilical vein endothelial cells. Eur J Pharmacol. 2007;566(1-3):1-10. https://doi.org/10.1016/j. ejphar.2007.03.006

PMid:17434478

53. Ma T, Kandhare AD, Mukherjee-Kandhare AA, Bodhankar S. Fisetin, a plant flavonoid ameliorates doxorubicin-induced cardiotoxicity in experimental rats: The decisive role of caspase-3, COXII, cTn-I, iNOs and TNF- $\alpha$. Mol Biol Rep. 2019;46(1):105-18. https://doi.org/10.1007/s11033-018-4450-y

PMid:30362071

54. Schmelzer C, Lindner I, Rimbach G, Niklowitz P, Menke T, Doring F. Functions of coenzyme Q10 in inflammation and gene expression. Biofactors. 2008;32(1-4):179-83. https://doi. org/10.1002/biof.5520320121

PMid:19096114

55. Schmelzer C, Lorenz G, Lindner I, Rimbach G, Niklowitz P, Menke $\mathrm{T}$, et al. Effects of coenzyme Q10 on TNF-alpha secretion in human and murine monocytic cell lines. Biofactors. 2007;31:35-41. https://doi.org/10.1002/biof.5520310104 PMid: 18806307

56. Martinez-Ruiz A, Lamas S. Signalling by NO-induced protein S-nitrosylation and S-glutathionylation: Convergences and divergences. Cardiovasc Res. 2007;75(2):220-8. https://doi. org/10.1016/j.cardiores.2007.03.016

PMid:17451659

57. Forman HJ, Davies KJ, Ursini F. How do nutritional antioxidants really work: Nucleophilic tone and parahormesis versus free radical scavenging in vivo. Free Radic Biol Med. 2014;66:24-35. https://doi.org/10.1016/j.freeradbiomed.2014.05.012 PMid:23747930

58. Finkel T. Signal transduction by reactive oxygen species. J Cell Biol 2011;194(1):7-15.

\section{PMid:21746850}

59. Ning C, Gao X, Wang C, Huo X, Liu Z, Sun H, et al. Hepatoprotective effect of ginsenoside Rg1 from Panax ginsengon carbon tetrachloride-induced acute liver injury by activating Nrf2 signaling pathway in mice. Environ Toxicol. 2018;33(10):1050-60. https://doi.org/10.1002/tox.22616 PMid:29964319

60. Tarry-Adkins JL, Fernandez-Twinn DS, IP, Neergheen V, CE, Martin-Gronert MS, et al. Coenzyme Q10 prevents hepatic fibrosis, inflammation, and oxidative stress in a male rat model of poor maternal nutrition and accelerated postnatal growth. Am J Clin Nutr. 2016;103(2):579-88. https://doi.org/10.3945/ ajcn.115.119834

PMid:26718412

61. Choi HK, Pokharel YR, Lim SC, Han HK, Ryu CS, Kim SK, et al. Inhibition of liver fibrosis by solubilized coenzyme Q10: Role of NRF2 activation in inhibiting transforming growth factor-beta-1 expression. Toxicol Appl Pharmacol. 2009;240:377-84. https:// doi.org/10.1016/j.taap.2009.07.030

PMid: 19647758

62. Zhang YY, Meng C, Zhang XM, Yuan CH, Wen MD, Chen Z, et al. Ophiopogonin $\mathrm{D}$ attenuates doxorubicin-induced autophagic cell death by relieving mitochondrial damage in vitro and in vivo. J Pharmacol Exp Ther. 2015;352(1):166-74. https:// doi.org/10.1124/jpet.114.219261

PMid:25378375

63. Madonna E, Kamel F, Mohammad HMF, Maurice C, Hagras MM. Ginseng nanoparticles protect against methotrexate-induced testicular toxicity in rats. Egypt J Basic Clin Pharmacol. 2019;9:101397. https://doi.org/10.32527/2019/101397

64. Vasiliev AV, Martinova EA, Sharanova NV, Gapparov MM Effects of coenzyme Q10 on rat liver cells under conditions of metabolic stress. Bull Exp Biol Med. 2011;150(4):416-9. https:// doi.org/10.1007/s10517-011-1156-8

PMid:22268031 